Chapter from:

Genetic and Cultural Evolution of Cooperation

Edited by P. Hammerstein, 2003

ISBN 0-262-08326-4 C) The MIT Press

\title{
6 \\ The Bargaining Model of Depression
}

\author{
Edward H. Hagen \\ Institute for Theoretical Biology, Humboldt University, 10115 Berlin, Germany
}

\begin{abstract}
Minor depression - low mood often accompanied by a loss of motivation — is almost certainly an adaptation to circumstances that, in ancestral environments, imposed a fitness cost. It is, in other words, the psychic equivalent of physical pain. Major depression is characterized by additional symptoms - such as loss of interest in virtually all activities and suicidality - that have no obvious utility. The frequent association of these severe and disabling symptoms with apparently functional symptoms, like sadness and low mood, challenges both dysfunctional and functional accounts of depression. Given that the principal cause of major unipolar depression is a significant negative life event, and that its characteristic symptom is a loss of interest in virtually all activities, it is possible that this syndrome functions somewhat like a labor strike. When powerful others are benefiting from an individual's efforts, but the individual herself is not benefiting, she can, by reducing her productivity, put her value to them at risk to compel their consent and assistance in renegotiating the social contract so that it will yield net fitness benefits for her. In partial support of this hypothesis, depression is associated with the receipt of considerable social benefits despite the negative reaction it causes in others.
\end{abstract}

\section{DEPRESSION IS STILL A MYSTERY}

After more than a century of inquiry, unipolar depression remains a profound scientific mystery. Like people working on a large and difficult jigsaw puzzle, researchers in genetics, biochemistry, cognitive psychology, social psychology, and psychodynamics have pieced together detailed accounts of depression from their various theoretical vantage points, but these disparate views have yet to be integrated into a single, coherent whole. Just as an unfinished puzzle often reveals itself in parts that give little clue of the final picture, depression is well understood in aspects, yet no one can answer the question: What, ultimately, is depression? Recent personal problems are clearly implicated in its onset, and 
psychotherapy — talking about these problems — has been shown to be about as effective in reducing depressive symptoms as the latest antidepressants (U.S. Department of Health and Human Services 1993). These facets of depression must be reconciled with the equally significant genetic and biochemical correlates. As the editor of a recent volume on depression concluded, "Despite a great deal of thorough research there is no agreement concerning etiology, symptomatology, and treatment methods" (Wolman 1990, preface). The editor's choice of terminology reflects what is perhaps the single point of agreement among depression researchers: major depression is an illness.

With no consensus on causes, symptoms, or treatment, little-to-no evidence that depression in general is caused by infections, toxins, or physical injury to the brain, excellent evidence that depression is caused by social circumstances that would have occurred repeatedly in the environment of evolutionary adaptedness (EEA) — often dangerous social circumstances in which a genuine cognitive impairment would have been disastrous - and given that most sufferers of depression experience a complete recovery often in association with (and possibly caused by) major life improvements like getting a better job or relationship, one wonders why there is such conviction that depression is a mental illness. Several unpleasant experiences such as physical pain and nausea are in fact adaptations designed to protect the sufferer from harm.

In the first part of this chapter I will argue that there was a selection pressure for the evolution of a bargaining strategy in humans; in the second, I will argue that clinical, unipolar depression may be just such a strategy.

\section{THE INDIVIDUAL VERSUS SOCIETY IN THE EEA}

In the EEA, costly conflicts between individuals and groups were probably common, particularly in the wake of individual social losses and failures. Individuals suffering social losses or failures often need assistance, additional material or social resources, or to renegotiate their relationships with group members. Social partners could not be expected to provide help or make changes immediately, however, particularly when they were benefiting from the status quo.

Conflicts between individuals are common in many species and often result in physical aggression because injuring, or threatening to injure, others is an effective means of influencing or deterring their actions (Clutton-Brock and Parker 1995; McElreath 2003). In humans, this strategy is closely identified with the emotion anger (Fessler 2003). There is, however, a key limitation to an aggressive strategy. In the EEA, it would have been difficult for a single individual to use aggression when one's opponent was physically more formidable, or when one was opposed by a group. If one needed to influence the behavior of a single powerful individual or a group, physical threats (especially by a female) would rarely have been effective: even two people can almost always overpower one. 
Persuasion was also an option, but if an individual's claims were difficult to verify and/or if inherent conflicts of interest existed among the parties, persuasion was likely to fail. Consequently, an effective strategy to compel assistance or change would have provided substantial fitness benefits. The solution proposed here is that one could have efficiently imposed costs on powerful others, thereby influencing them, by withholding benefits that one provided them until desired changes were forthcoming. In other words, individuals could bargain.

\section{BARGAINING}

\section{Social Conditions in Which Bargaining Can Be Effective}

Bargaining, the withholding of benefits to compel changes by others, can only work, and is only necessary, in particular social circumstances - circumstances that were likely to have been ubiquitous in the EEA.

\section{Viscous Social Markets and Monopoly Power}

When there are many resource providers, i.e., when there is a market instead of a monopoly, one has little need to pay a cost to influence others because one can always obtain the necessary resources elsewhere (resource costs are then determined by the supply and demand curves of standard economic theory). ${ }^{1}$ In the EEA, however, it may frequently have been the case that there was little-to-no market; all parties often had effective monopolies on resources that were crucial to other group members. Kin- and family-based social organization, high levels of biparental care, low population densities, ethnicity, and occasional intergroup aggression meant that switching social partners was difficult.

It would have been difficult, for example, for mothers to raise offspring without help from the father and/or other family members; conversely, the fitness of the father, parents, and other family members depended critically on the mother successfully raising offspring. Abandonment of one party by another would have entailed a significant fitness cost to all (for further details, see Hagen 1999). In another typical example, political alliances between families may have often depended on an arranged marriage between a man from one family and a woman from the other, as is commonly seen in contemporary hunter-gatherer groups (Rodseth et al. 1991). If so, important political relationships between families depended critically on sons and daughters; conversely, sons' or daughters' relationships with their families depended critically on their willingness to participate in the arranged marriage.

1 If there is a market on only one side, the single seller (monopoly) or single buyer (monopsony) sets the price unilaterally. 


\section{Contract Enforcement}

Partners can also maintain an effective monopoly on resources they provide, thereby ensuring their personal importance to others, when they can exclude competitors or when they can easily punish defection, both likely important aspects of ancestral social environments. Punishing defectors, in particular, is increasingly recognized as an important social strategy (e.g., Boyd and Richerson 1988, 1992). The ability to impose costs efficiently on defectors raises the specter that individuals who do not benefit from a cooperative venture could nonetheless be forced to participate despite the fitness costs they might suffer.

In sum, the market for certain kinds of social partners in the EEA may often have been anything but fluid. Given this high degree of interdependence in foraging bands (see also Boehm 1996), individuals who withheld benefits would have imposed significant costs on other band members.

\section{When to Bargain}

Individuals should attempt to compel assistance when they suffer high costs that can be alleviated by others. Such costs can have many causes but can frequently come in the wake of social losses and failures; when critical social strategies fail, the benefits one is receiving plummet. Increased benefits may be possible, however, if others are willing to provide assistance or make major social changes. In the EEA, individuals could have suffered social losses and failures in numerous ways. Important social partners such as mates and allies could have died or severed relations, forcing one to abandon the current strategy; social strategies could have failed to realize fitness benefits, such as when efforts to increase or maintain social status failed, or when a mateship yielded a low viability infant; competitors could have blocked access to critical resources, including key social relationships; one could have been coerced by powerful others; one could have been betrayed by social partners; one could have been prevented from pursuing new, more profitable opportunities; or one could simply have chosen the wrong strategy or executed it poorly.

In many such cases, individuals could have unilaterally pursued an alternative strategy, like finding a new mate after the death of a spouse. If evidence from contemporary small-scale societies is any guide, however, in many other cases, individuals often required the consent and/or cooperation of group members to mitigate the costs of social failures. If a husband were abandoned by his wife, for example, physical threats might have secured her return, but they might also have been counterproductive (Figueredo et al. 2001). If the husband could have convinced group members to spend political capital in securing the return of the wife or procuring another, chances of success would have been far greater. Unfortunately, there often could have been conflicts of interest between the individual and the group. Group members might not want to spend their political capital securing another mate for someone who had one, but lost her due to his 
abusive behavior, or because the group preferred using its capital to secure a mate for a higher status individual. In another example, arranged marriages are frequently made with little regard for the personal preferences of those to be married. Those betrothed to an undesirable mate often face formidable opposition from their families and other group members, however, if they resist the marriage (e.g., Shostak 1981). This opposition could exist because there is a genuine conflict of interest between the parties, or because the family and group members simply have little reliable information about the relative quality of the mates (and thus would not want to make costly changes for an unknown benefit).

Given that even relatively high degrees of relatedness, although important, appear insufficient to sustain cooperation in foraging bands, given the high mutual interdependence of individuals in these bands, and given that small cooperative groups of foragers only had the time and resources to achieve limited goals, which might not meet the needs of all members, conflicts between individual members and the group were inevitable. This was especially so when one member was suffering costs that others were not. Individuals therefore needed a strategy to pressure other group members to alleviate these costs despite conflicts of interest or concern about their legitimacy.

As a consequence of viscous social markets, enforcement of social contracts, and conflicts of interest, there was a strong selection pressure among humans to evolve bargaining strategies to compel assistance and/or modification of social arrangements that were no longer profitable. Bargaining is necessary and effective when (a) at least one participant is not benefiting from the current social contract, (b) others are benefiting from the social contract, and (c) participants have a monopoly or near monopoly on the resources they provide - otherwise, disaffected parties could simply choose to cooperate with someone else (for a review, see Kennan and Wilson 1993).

\section{Private Information and Credible Signaling: The Function of Delay}

When the value of cooperation decreases with time, withholding benefits can also credibly signal that one is truly suffering costs to those who might not otherwise recognize those costs. It is difficult for group members to assess the costs and benefits incurred by their social partners accurately: she claims she is not benefiting from a relationship, but perhaps she really is and just wants more than her fair share; her true valuation is private information.

The discount factor, $\delta$, is the fraction of cooperative benefits still available after each round of bargaining and is thus a measure of delay costs due to multiple rounds of bargaining. Kennan and Wilson (1993) argue that quick agreements are usually possible in most models of bargaining where valuations and discount factors are common knowledge (i.e., no private information). Informally, if each participant knows what the other participants know, each will come to the same conclusions about how any sequence of bargaining rounds will proceed; each participant will also come to the same conclusions about the "optimal" outcome 
for other participants, and thus this outcome can be offered in the first round. In a simple game of alternating offers by a buyer and seller, if $0<\delta<1$, then the maximum benefit decreases as $\delta^{t}$, where $t$ represents the number of rounds. The seller must make an offer just sufficiently generous such that the buyer cannot do better by waiting another round - when delay is costly, each party has an incentive to minimize the number of rounds of bargaining in order to maximize benefits. It can be shown that if the seller makes the first offer, she will offer a price that gives her $1 /(1+\delta)$ of the benefits, which the buyer accepts immediately (Rubinstein 1982).

If, however, participants in a cooperative venture do not know how other participants value the potential benefits or the costs they will suffer from delays, as was often likely in the EEA, it will be impossible for all participants to reach the same conclusion about the "optimal" agreement. If participants could credibly signal to other participants their true valuations and discount factors, then an agreement could be reached. Kennan and Wilson (1993) argue that the willingness of a participant to suffer the costs of multiple rounds of bargaining (due to discount factors less than one), coupled with the sizes of the offers made each round, represents credible information about that participant's true valuation - a greater willingness to delay signals lower valuations (because the more valuable the potential benefits from cooperation are to a participant, the less she can afford to delay). Once each participant acquires a relative level of certainty about the other participants' private valuation by observing their willingness to incur delays, the bargaining game becomes equivalent to one where valuations and discount factors are public knowledge, and an agreement can be quickly reached.

I argue that the costly symptoms of depression have a function, and that function is to impose costs efficiently on other group members by withholding critical benefits, credibly signaling to them that one is suffering costs (Watson and Andrews 2002), and compelling them to provide assistance or make changes. According to this view, depression is an (unconscious) social manipulation strategy that is triggered when individuals perceive that they are suffering costs that can only be alleviated by the actions of fellow group members (Hagen 1996, 1999, 2002; MacKey and Immerman 2000; Watson and Andrews 2002). Much as striking workers withhold benefits to impose costs on management, in the hope of inducing an increase of wages, a depressed individual may be strategically reducing productivity to impose costs on fellow group members, hopefully inducing them to act in ways more beneficial to her. To paraphrase Clausewitz, depression is the continuation of personal politics by other means.

\section{MAJOR UNIPOLAR DEPRESSION: AN OVERVIEW}

The two major classification systems of psychiatric disorders, ICD-10 and DSM-IV, both recognize that in typical depressive episodes, the individual 
Table 6.1 Symptoms of a major depressive episode according to DSM-IV (APA 1994) and their hypothesized functions in the bargaining model. Bracketed text indicates functions that require additional assumptions. The diagnostic criteria for a major depressive episode are that an individual experiences either symptom one or symptom two, and at least four of the remaining seven symptoms nearly every day for a period of not less than two weeks.

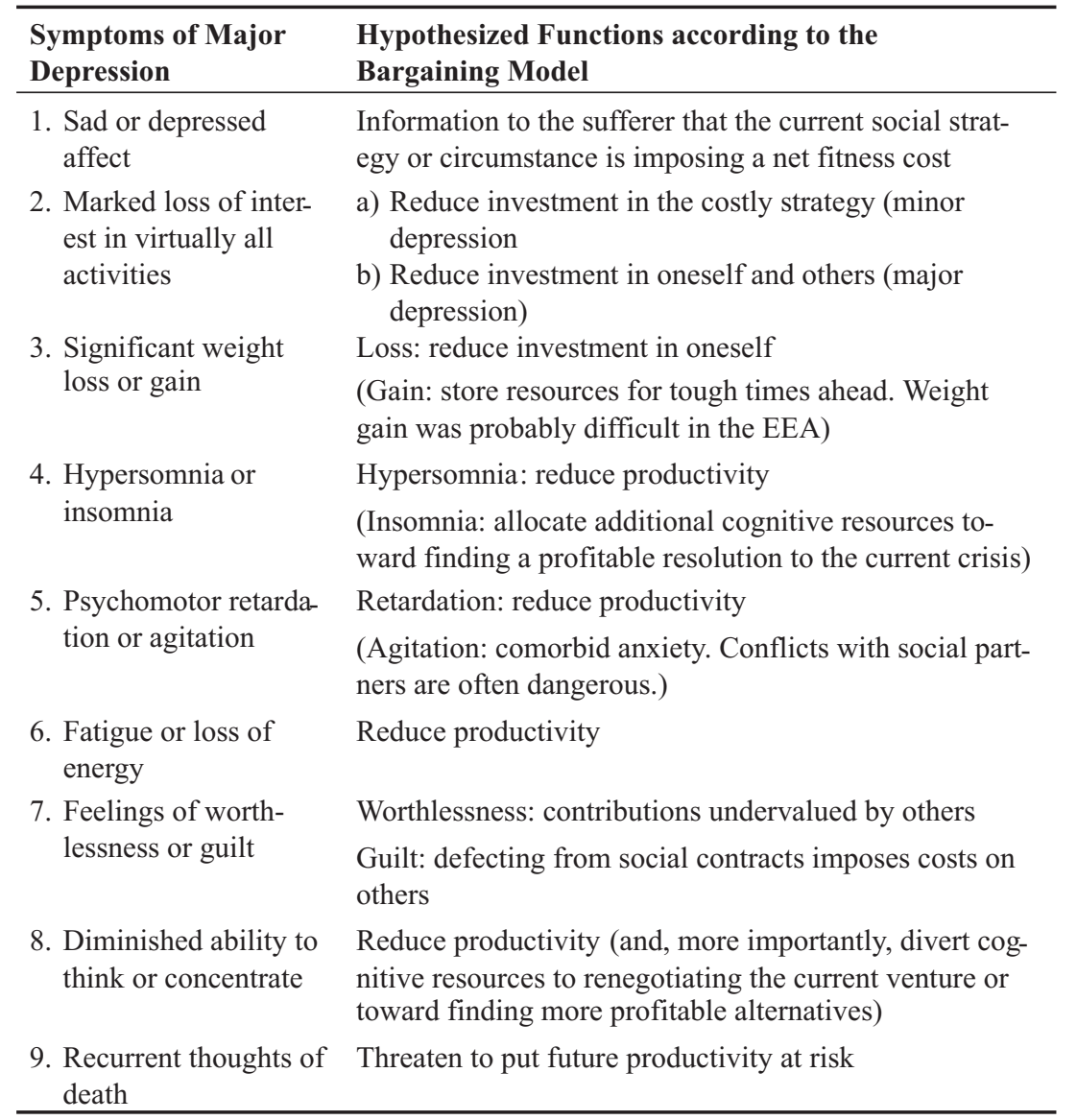

suffers from depressed or sad mood, loss of interest and enjoyment, reduced energy, and diminished activity. This suite of emotions and behaviors has been observed in virtually all human societies (Patel 2001). ${ }^{2}$ Table 6.1 provides an overview of the symptoms and their hypothesized functions (note: bipolar depression will not be discussed).

2 Asians may be more willing to report somatic symptoms relative to cognitive or affective symptoms, but it appears that they are just as likely to experience cognitive and affective symptoms as are Westerners; similarly, somatic symptoms are the most commonly reported by Westerners as well (Patel 2001). 
Any theoretical explanation of depression must account for the following characteristics of depression: low mood and loss of interest in virtually all activities, a significant reduction in productivity, suicidality, a possible negative impact on health, a cross-culturally robust 2:1 female bias, a relatively high worldwide annual prevalence rate of around 5-10\% (WHO 2001; rates vary widely by country), the substantial evidence that depression is closely associated with chronic activation of the hypothalamic-pituitary-adrenal axis (HPA) (e.g, Nemeroff 1996) — which prepares the body for fight-or-flight — and the fact that the most significant known cause is a major, negative life event. More on each of these below.

\section{LIMITATIONS OR PROBLEMS WITH PREVIOUS ADAPTATIONIST HYPOTHESES FOR DEPRESSION}

The challenge for an evolutionary account of depression is to reconcile the close association of plausibly functional symptoms (e.g., sadness and loss of interest in some activities) with its many costly symptoms (e.g., suicidality). The most theoretically coherent and empirically supported hypothesis for minor depression (a much less severe form of major depression) is the "psychological pain" hypothesis (Alexander 1986; Hagen 1999; Nesse 1991; Suarez and Gallup 1985; Thornhill and Thornhill 1989; Tooby and Cosmides 1990; Watson and Andrews 2002). Whereas physical pain functions to inform individuals that they have suffered a physical injury - motivating them to cease activities that would exacerbate this injury, as well as to avoid similar future situations which would also likely result in such an injury — psychological pain informs individuals that their current social strategy or circumstance is imposing a fitness cost, motivating them to cease activities that would exacerbate this cost, as well as to avoid similar future situations which would also likely result in a fitness cost. Such circumstances include, e.g., the death of children and relatives, loss of status, loss of a mate.

The "social competition" or "social yielding" hypothesis similarly proposes that short-term depression is an adaptation to force the loser of a social conflict involving status or rank (a) to stop competing with the winner, (b) to accept the fact that s/he has lost, and (c) to signal submission, thereby avoiding further conflict with the winner (Price et al. 1994). The "yielding" hypothesis obviously has much in common with the "psychic pain" hypothesis and is probably best considered an important, special case of the latter - loss of a social competition is certainly a prime example of a social circumstance that imposes a fitness cost, and the pain of depression could quite plausibly motivate losers to cease competing, thus avoiding the costs of continuing a futile competition. The yielding hypothesis cannot be a complete explanation for even minor depression, however, because loss of a social competition is not its only cause — having a baby with temperament problems (C.T. Beck 1996) is but one well-documented cause of depression that does not involve losing a status competition. 
Neither the yielding hypothesis nor the psychic pain hypothesis accounts for major depression, and comments by proponents of these theories suggest that they are not intended to. Losers of social competitions should yield quickly, so proponents of the yielding hypothesis (Price et al. 1994) logically argue (from their perspective) that severe and prolonged depression is maladaptive (a major depressive episode can typically persist for months). Similarly, Nesse (1999, p. 356), a proponent of the psychic pain hypothesis, suggests that "sadness is almost certainly adaptive, but depression may arise from dysregulated sadness or from an entirely separate mechanism." A pronounced and sustained loss of interest and enjoyment in virtually all activities, loss of energy, and diminished activity are core features of major depression. Some psychic pain theorists (Tooby and Cosmides 1990, 2000; Nesse 2000) have cogently argued that, in the face of a major social failure, one should take pause. Immediately pursuing another social strategy without first evaluating the recent failure would likely only lead to another, costly failure. A distinction must be made, however, between a short-term reluctance to pursue one's social strategies, which often would have been wise in such circumstances, and long-term reduced self-care, which does not improve analysis of social failures or ability to unilaterally respond to social opportunities. Except when faced with an immediate threat, individuals simply analyzing a social failure should never stop eating, bathing, and grooming; individuals who did so in the EEA would have found that their health deteriorated rapidly, with (under this hypothesis) no compensating benefits.

Not only does depression have a significant, long-term negative impact on productivity, there is, as will be briefly discussed below, legitimate concern that the lack of self care accompanying depression may cause increased mortality, even in populations with ready access to resources and sophisticated medical care. Suicidality is also a very common symptom of major depression, yet there is no reason for an individual who has suffered a severe fitness cost, such as losing a social competition, to contemplate imposing additional costs on herself - especially the ultimate cost of death!

Energy conservation is another commonly proposed function for depression (e.g., A. Beck 1996). Although energy conservation was certainly an important reproductive problem in the EEA, depression does not show evidence of having been well designed by natural selection to solve it. Depression has some features that would reduce energy consumption, such as psychomotor retardation, but it has many features that have nothing to do with energy conservation, such as the intensely negative emotions that are the hallmark of depression. Neither fatigue nor sleep, two recognized energy-conserving adaptations, are associated with such intensely negative emotions in nondepressed individuals. Similarly, why would depression often be associated with loss of appetite when food is available? If it were an adaptation to resource-poor conditions, the opposite should always be the case. Why would depression be associated with insomnia, intense social rumination, or psychomotor agitation, which increase energy 
consumption? Why would it often be associated with feelings of guilt or anxiety? In sum, the symptoms of depression would have added nothing to, and would often have subtracted much from, the efficacy of fatigue and sleep as energy-conserving adaptations.

A common and reasonably compelling hypothesis is that depression is an evolved signal of social need (Lewis 1934; Henderson 1974). Many human emotions are closely associated with facial expressions and other types of signaling such as laughing and crying. Could the symptoms of depression, including suicide threats, simply be costly and therefore credible signals of need? However theoretically attractive this hypothesis, it is not supported by the evidence. Research has clearly shown that individuals react negatively to people who are depressed or exhibit symptoms of depression (Segrin and Dillard 1992), precisely opposite the desired reaction if depression were merely a generic signal of social need. ${ }^{3}$

In general, the symptoms of major depression seem designed to prevent the acquisition of benefits. A marked loss of interest in virtually all activities, significant weight loss, psychomotor disturbances, fatigue or loss of energy, and suicidal ideation would all have impeded ancestral humans from engaging in critical, beneficial activities, such as food gathering and consumption, buffering food shortages, personal hygiene, avoiding environmental hazards, information gathering, helping relatives and friends, etc. An adaptationist account of major depression must incorporate, not avoid or reinterpret, its costly symptoms.

\section{MAJOR UNIPOLAR DEPRESSION AS A BARGAINING STRATEGY}

\section{Social Losses, Failures, and Other Causes of Depression}

Numerous studies have shown that circumstances in which individuals may need to compel social assistance — adverse life events — are a potent cause of depression (Kendler et al. 1995; Mazure et al. 2000). Kendler et al.'s (1993) etiologic model of depression among female twins captures the essentials as well as any. In a longitudinal study of 680 female-female twin pairs, Kendler et al. found that the strongest predictors of a major depressive episode were, in descending order, (a) recent stressful life events, (b) genetic factors, (c) previous history of major depressive disorder, and (d) neuroticism. Their full, nine-variable model explained $50.1 \%$ of the variance in liability to depression (see also Kendler et al. 2002). For illustration, the four adverse life events which predicted onset of major depression in women with an odds ratio of 10 in a study by Kendler et al. (1995) were death of a close relative, assault, serious marital

3 Note that, despite the negative feelings engendered by depression, actual rejection would have been difficult for most group members in the EEA if the depressed person had a monopoly on benefits they provided to the group. 
problems, and divorce/breakup. Cross-culturally, depression case rates strongly covary with rates of adverse life events (Brown 1998).

Decades of research have shown that postpartum depression (PPD) is similar, if not identical, to depression in general (e.g., Whiffen and Gotlib 1993), and is therefore a good model for depression. ${ }^{4}$ Human mothers should not automatically invest in offspring, but rather should weigh the decision carefully based on infant viability, levels of social support, access to resources, negative consequences for their other children, etc. (Trivers 1972; Clutton-Brock 1991). There is excellent evidence that lack of social support is a cause of PPD and substantial evidence that problems with the pregnancy, delivery, or infant, lack of resources, and concern about their ability to care for their other children are also closely associated with PPD (Hagen 1999). Childrearing costs that others could mitigate appear to cause PPD.

\section{Social Constraints: Viscous Social Markets and Monopoly Power}

A key prediction of the bargaining model is that depression should be caused not simply by loss, failure, and other social costs, but also by circumstances where individuals cannot unilaterally alleviate these costs. There is considerable evidence that this is the case. A perceived inability to control events — variously termed external locus-of-control (e.g., Rotter 1966), helplessness or hopelessness (Abramson et al. 1989), or entrapment (Brown 1998) — is clearly implicated in depression.

Meta-analyses of nearly 100 studies (Benassi et al. 1988; Presson and Benassi 1996) found that external locus-of-control and depression were significantly related, that the relation was moderately strong, and that it was consistent across studies; in addition, a belief that events were controlled by powerful others and chance was associated with higher levels of depression. Under the bargaining model, depression is a strategy to redress the causes of helplessness/ hopelessness/lack-of-control/entrapment and that is why depression is expected to be associated with them. In the EEA, even seemingly irredeemable losses, such as the abandonment by or death of a spouse, could often have been readily addressed by powerful individuals in one's social group.

Studies of PPD also support the contention that constraints on unilateral action are associated with depression. Hagen (2002) found that for mothers in general, there was no correlation between social constraints on abortion and their PPD levels, nor should there have been. A social constraint on abortion is inconsequential for mothers who want the new child. The depression scores of mothers with unwanted or unplanned pregnancies, however, significantly positively correlated with their perception that having an abortion would damage their

4 PPD has a number of methodological advantages in the study of depression; e.g., it is easy to identify a population — pregnant women — who will be experiencing a stressful and potentially costly life event — birth — at a predictable point in time. 
relationship with their spouse (there was, however, an interesting nonlinearity). Because mothers' perceptions could have been biased by their depression levels, fathers were also asked to report how much damage a wife's abortion would have caused their relationship. Fathers' perceptions of damage also correlated with mothers' depression levels, suggesting that actual, and not merely perceived, social constraints on reproductive decision making are associated with PPD.

Men's reproductive decisions are also constrained. Men, but not women, can substantially increase their reproductive success by mating with multiple partners. Hence, the opportunity cost of socially imposed monogamy is predicted to be much higher for men, especially during the postpartum period when their nursing wives are infertile, encumbered with a new infant, and therefore significantly hindered from finding other mates. This cost, however, will only be borne by men who have additional mating opportunities. Hagen (2002) found exactly this. Men with more sexual opportunities were more depressed postpartum, whereas women with more sexual opportunities were not. About one half the effect for men was found to be due to relationship problems, whereas the other half was due simply to sexual opportunities.

\section{Conflicts of Interest and Private Information in the EEA}

In the bargaining model, a need to influence others plus the inability to act unilaterally are necessary, but not sufficient, to cause major depression. There must also be a conflict of interest between group members and the individual, a conflict that can arise, in part, from private information (if there were no conflict, group members would simply provide the needed benefits). Note that this conflict need not be overt nor even consciously recognized by those involved. Although the evidence presented above certainly suggests a conflict with others, there is also considerable direct evidence that social conflict is involved. In a meta-analysis of 48 studies, Finch et al. (1999) found that social negativity had a significant correlation with depression in the expected direction, and results of longitudinal studies suggest a causal influence of negative social interactions on subsequent depression (e.g., Vinokur and van Ryn 1993); depression may, in turn, exacerbate social negativity (e.g., Coyne 1976). A follow-up study by Finch et al. (1999) suggests that interference/hindrance, anger, and insensitivity are the three aspects of social negativity that are most salient as predictors of depression. Each seems relevant to the bargaining model.

Because changing social relations within a group can be a difficult and costly affair, most group members will resist such a change without clear evidence that it is necessary (Watson and Andrews 2002); otherwise group members could easily be exploited by deceptive individuals. If the individual has information that she is suffering a cost, but the other group members do not, the individual must credibly communicate this private information to others. Because this is a 
novel aspect of the bargaining model, there is no evidence (yet) that private information is associated with depression. It is very likely, however, that individuals often had private information about their costs and benefits in important cooperative ventures. Childrearing provides a nice example. The mother, having carried the child for nine months, may have considerable information about its health that is unavailable to either the father or other family members, or she may have information about her own health that necessitates changing her levels of investment.

\section{Withholding Benefits and the Costs of Delay}

Withholding benefits until better terms are forthcoming (asserting monopoly power) is the essential feature of any bargaining strategy and is one of the central functions of depression proposed here. In addition, the willingness of a depressed individual to delay investment in a cooperative venture is a credible signal to her social partners that the endeavor is unprofitable (Watson and Andrews 2002). Conversely, the degree of reluctance of other participants to increase the benefits they are providing is an equally credible signal of their true valuation of the venture: the longer they are willing to delay, the less they value the venture. It is important to note that depression is not simply a costly and therefore honest signal of social need (Spence 1974; Zahavi 1975). First, in the classic theory of costly signaling, the recipient of the signal does not incur a cost, only the sender (ignoring the relatively small costs of signal detection). This is not the case in the bargaining model of depression. The recipients of the signal (group members) may incur substantial costs; this, in fact, is a principal objective of the strategy.

Second, although it is widely assumed that costs guarantee the honesty of a signal, it is not the costs of a signal per se but rather that inherent aspects of the signal necessarily distinguish between individuals in different states. Here, the sender, - the depressed person - may incur little or no fitness cost when sending a credible signal. Consider, for example, the extreme case of a worker who is paid nothing, but whose boss profits handsomely from her labor. Because she has no wages to lose, it costs her nothing to go on strike, but it costs her boss plenty. Her willingness to delay working indefinitely is a credible (but not costly) signal of her low valuation of her current salary. Similarly, there would have been little fitness difference between an indissoluble marriage to an infertile mate and a complete cessation of all activities, including feeding and self care. The "message" of depression is that, for the sufferer, there is little difference in the fitness benefits obtained from investing heavily in her current social strategy or investing little. Depression is a credible signal because individuals who are profiting from their social strategies cannot afford the delay required to send it. Depression is a relatively affordable (and therefore sendable) signal only for those senders whose social circumstances are imposing significant opportunity costs. 
Consistent with the bargaining model's requirement that depression cause a reduction in benefits generated by the afflicted individual, a loss of interest in virtually all activities is a prominent symptom of major depression, and depression has a very significant, negative impact on productivity. Worldwide, it is the leading cause of disability as measured by YLDs, and the fourth leading contributor to the global burden of disease (DALYs) in 2000.5 Depression is the second most significant cause of DALYs in the age category 15-44 years for both sexes combined (WHO 2001). Wells et al. (1989) found that the poor functioning uniquely associated with depressive symptoms (with or without depressive disorder) was comparable to, or worse than, that uniquely associated with eight major, chronic medical conditions. For example, the unique association of days in bed with depressive symptoms was significantly greater than the comparable association with arthritis, diabetes, and hypertension. ${ }^{6}$

Further, numerous studies have found a significant impact of depression on mortality rates, suggesting that either depression itself, or the poor self-care caused by its symptoms, or both, might have an important negative impact on health. Unfortunately, most of these studies did not sufficiently control for important associated health risks like smoking and alcohol use. As a recent systematic review of the mortality of depression concluded (Wulsin et al. 1999, p. 15):

The existing body of studies, so rich with mixed findings and so lean in the numbers of well-controlled comparable studies, suggests a substantial effect of depression on mortality in some populations, but to estimate the true size and the source of this effect (whether it is a direct result of the pathophysiology of depression or the indirect result of poor self-care) will require more rigorous study.

In the postpartum model, mothers with PPD should (a) experience a loss of interest in the infant and (b) actually reduce their investment in the infant. As predicted, loss of interest in the infant is a major symptom of PPD. In addition, mothers with PPD unequivocally reduce their investment in the new offspring along virtually every dimension at the same time that they appear to have reached a negative assessment of the childrearing venture. In the EEA, such reduced care would have had a serious negative impact on infant, and therefore family members' fitness (Hagen 1999).

5 "DALYs for a disease are the sum of the years of life lost due to premature mortality (YLL) in the population and the years lost due to disability (YLD) for incident cases of the health condition. One DALY can be thought of as one lost year of 'healthy' life." (WHO 2001, p. 25)

6 Depression is also associated with serious physical illness. There is a well-documented elevated risk of acute coronary syndromes in persons with major depression, which may be caused by the increased platelet reactivity/aggregability that has been observed in depressed patients (because these increase risk of intra-arterial thrombus formation, i.e., clotting) (e.g., Shimbo et al. 2002). An obvious interpretation of these findings is that, in the EEA, a social threat of the type hypothesized to cause depression frequently resulted in physical injury; thus, blood clotting system is on "high alert." 
Given the time-sensitive nature of most human cooperative activities (e.g., foraging, territorial defense, and parenting), the withholding in the EEA of the benefits documented above would have certainly imposed the costs of delay on others required by the bargaining model. Even if an individual did not receive increased investment as a consequence of bargaining, she would have credibly signaled her low valuation of this cooperative venture to her social partners and would have received credible information from her social partners regarding their valuation of the venture. This information would have been of considerable utility for her future strategic decision making.

\section{Does Depression Elicit Benefits?}

Critical to the bargaining hypothesis is evidence that depression can improve one's social environment (or would have in the EEA). Just as management would react negatively to a labor strike but still be forced to provide benefits, depression should cause negative reactions in others yet still elicit benefits from them. The substantial evidence that depression causes negative reactions in others (Segrin and Dillard 1992) implies conflict. Does depression nonetheless elicit benefits? For much of the last century in the West, researchers have viewed depression as an illness, so studies investigating its power to work deep, and ultimately positive, long-term changes in the lives of those afflicted have been few-to-none. However, accounts of depression's transformative capabilities are frequently found in the penetrating autobiographies of those who have known the "black dog" (e.g., Jeffery Smith's Where the Roots Reach for Water).

In comparison to the current lack of objective evidence for long-term benefits, there is solid evidence that depression elicits short-term benefits. Before presenting the evidence for the benefits that are obvious predictions of the bargaining model, the rationale for an additional benefit — reduced risk of punishment - will be developed. Unilateral defection from a cooperative relationship, as occurs in the bargaining model, invites punishment for cheating (e.g., Axelrod and Dion 1988). If those choosing to withhold benefits could convince others that, despite not providing benefits, they were not taking benefits either, they might be able to avoid punishment for cheating, at least in the short term. The behavioral "shutdown" that characterizes major depression effectively prevents individuals not only from providing benefits, but also from taking benefits provided by others. It is important to have a thorough behavioral shutdown. Theoretical treatments of punishment and the evolution of cooperation make clear that error rates can be a critical parameter (e.g., Boyd and Richerson 1992). If group members mistakenly perceive that an individual is taking benefits but not reciprocating, they might impose devastating costs. A marked loss of interest in virtually all activities can significantly decrease the odds that the depressed individual will be perceived by anyone to be taking benefits.

A number of behavioral studies have demonstrated that although depression in one family member prompts negative feelings from other family members, it 
nonetheless appears to deter their aggressive behavior and to cause an increase in their tendency to offer solutions to problems in a positive or neutral tone and an increase in their solicitous behavior (e.g., caring statements), consistent with the bargaining model. ${ }^{7}$ In the short term, depression has also been shown to elicit help and support from nonfamily members (i.e., roommates) in naturally occurring as well as laboratory situations, although longer-term studies indicate high levels of hostility and a progressive decline in social contact and satisfaction with the depressed person. In non-EEA social settings where social partners such as roommates often do not have the power to make major social changes and are not dependent on the depressed, it is not surprising that depression continues unabated and that social partners elect to reduce social contact. For a review of this literature, see Sheeber et al. (2001). Behavioral studies thus confirm that depression causes an increase in provisioning of social benefits and a decrease in aggressive responses, as predicted.

Similarly, the spouses of individuals experiencing PPD should report increasing their investment in parenting, and in fact they do. Depression scores for one spouse were positively correlated with reports of increasing investment in childcare by the other spouse (Hagen 2002). High levels of help from spouses and better interactions with infants in one study were also the only variables associated with remission of PPD (Campbell et al. 1992).

Major life improvements are associated with remission of depression and may even play a causal role (citations in text omitted):

Even more thought-provoking was the investigation of the "meaning" of those fresh start experiences which, more often than not, preceded depressive remission.... Although all these data were collected retrospectively, the time order between these and remission, and the high proportion of such events which were independent of the subject's agency, lent plausibility to this being the effect of the environment on pathology. It seemed fresh starts were the mirror image of those producing the generalised hopelessness of Beck's depressive cognitive triad.... They either involved events like starting a new job after months unemployed, starting a course after years as a housewife, establishing a regular relationship with a new boy friend/girl friend after many months single, or the reduction of a severe difficulty, usually with interpersonal relationships, housing or finance. They seemed to embody the promise of new hope against a background of deprivation. It was notable that even for women who continued to experience difficulties of a depressogenic severity in one life domain such as marriage, a fresh start in another life domain — starting an access course — often seemed to tip the balance and set them on course for remission. (Harris 2001, p. 19)

It is not yet apparent whether depression symptoms themselves help enable "fresh starts" (or would have in the EEA), but this is, of course, precisely the proposed function of depression. It is therefore encouraging that "fresh starts" are closely associated with the remission of depression and may even cause it.

7 Oddly, such responses seem to be viewed negatively by researchers in this field because they are seen as "facilitating" or "reinforcing" depressive behavior. 


\section{Depression in the Ethnographic Record}

In small-scale, kin-based societies, which most closely resemble ancestral human communities, what little evidence exists suggests that depression occurs for the reasons predicted by the bargaining model, and that it has the predicted effects on the group. Among the Kaluli of the tropical forest in Papua New Guinea, for example, emotions (in general) and depression (in particular) must be understood for the roles they play in the system of reciprocity upon which Kalulian society is based (Schieffelin 1985). Emotions like grief and anger are appeals or demands to redress losses. If grief is an appeal to satisfy a "legitimate" claim, depression is an appeal to satisfy an "illegitimate" claim. Scheiffelin argues (p. 117) that depression should "arise in circumstances where an individual was placed unwillingly into a long-term life situation in which his or her assertive moves were regularly rebuffed or frustrated and in which there were no socially acceptable grounds for expressing anger or feeling owed." Thus, according to both Schieffelin and the bargaining model, grief should occur when there is a loss but little conflict between the individual and powerful others, and depression should occur when there is loss (more accurately, an opportunity cost) but a significant conflict between the individual and powerful others.

A careful study of an indigenous Quechuan malady, pena, which closely resembles depression (Tousignant and Maldonado 1989), also illustrates the impact of depressive symptoms on others in a small, kin-based society. Like major depression, severe cases of pena are characterized by a lack of concern for personal hygiene, loss of appetite often resulting in serious weight loss and dehydration, sleep disturbances, an inability to enjoy life, and a wish to die. Also, like major depression, pena is invariably associated with some kind of loss. Tousignant and Maldonado argue that pena functions to restore the balance of reciprocity upset by the loss and that "restitution of some form or another is the goal of the emotional strategy" (1989, p. 901). The impact of pena on the community closely matches the predictions of the bargaining model:

$[\mathrm{L}]$ ong periods of sadness in a woman will attract the attention of kin. They will investigate with whom the fault lies, usually suspecting the husband, and see in what way the situation can be corrected. In case of failure, the eldest adults of the community will get involved and, if discussions fail, more stringent admonitions and punishments, even flogging, may be applied. As was pointed out by McKee [unpublished ms], guilt is not the core element of punishment. The goal of the intervention is not to make the abuser ashamed but to facilitate reparation. (Tousignant and Maldonado 1989, p. 900)

Both Schieffelin (1985) and Tousignant and Maldonado (1989) argue that the meaning and social consequences of depression among the Kaluli and the Quechua can only be understood in the context of the central organizing principle of these societies: reciprocity. Given the ubiquitous importance of reciprocity in contemporary hunter-gatherer groups, depression may well have had the same meaning and social consequences among ancestral human foragers. 
The conceptualization of depression in some larger-scale traditional societies is also quite similar to the bargaining model. The Bengali illness concept mathar golmal (disturbance of the head), which appears to include depression, is an example. It is caused by "shock" such as the death of a loved one, business or career failures, or rejection by a lover (Bhattacharyya 1981, p. 153).

$[\mathrm{T}]$ hese emotional states all seem to point to frustration as a key cause. This frustration may be economic (money worries), academic (failure in exams), career (lack of advancement), or emotional (unrequited love). As several respondents have noted, being unable to obtain what is deeply desired is the source of frustration. The most extreme example of such frustration and the one most frequently cited is [intense grief] where the death of a loved one prevents the fulfillment of one's desires. Thus, the primary attribute of "shock" is an emotional response to an intensely frustrating situation. The gratification of desires is prevented because of some obstacle which makes the desired outcome beyond one's control, thus rendering one's own efforts totally ineffectual. (Bhattacharyya 1981, p. 201)

Consistent with the bargaining model, informants believe that the affliction "can be cured if the desires of the individual are met." Examples include obtaining a spouse or securing the return of a boyfriend (Bhattacharyya 1981, p. 203).

\section{Suicidality}

Depression and suicidality are deeply intertwined (see Table 6.2). Suicidality is a diagnostic symptom for major depression (Table 6.1), and depression is the most common mental disorder leading to suicide, although substance abuse and schizophrenia are also major contributors (WHO 2001). A successful theory of depression must explain suicidality, and the bargaining model, building on the work of Giddens (1964), Brown (1986), and Watson and Andrews (2002), does.

Suicide permanently removes oneself as a source of valuable benefits for the group. Suicide threats are therefore threats to impose substantial costs on group members and can be viewed as a means to signal cheaply and efficiently to a large social group that it may suffer such costs if assistance or change is not

Table 6.2 The close association of depression and suicide.

\begin{tabular}{|l|c|l|}
\hline Percent of suicides who had a mood disorder* & $60 \%$ & NIMH (2000) \\
\hline $\begin{array}{l}\text { Percent of severely depressed (inpatient population } \\
\text { treated for depression) who commit suicide }\end{array}$ & $4.4 \%$ & \\
\cline { 1 - 2 } $\begin{array}{l}\text { Percent of less severely depressed (mixed inpatient/ out- } \\
\text { patient population treated for depression) who commit } \\
\text { suicide }\end{array}$ & $2.2 \%$ & $\begin{array}{l}\text { Bostwick and } \\
\text { Pankratz (2000) }\end{array}$ \\
\cline { 1 - 2 } $\begin{array}{l}\text { Percent of those treated for nondepression illness who } \\
\text { commit suicide }\end{array}$ & $<0.5 \%$ & \\
\hline
\end{tabular}

* Major depression, bipolar disorder, dysthymia. 
forthcoming. Suicide attempts are necessary to underwrite the credibility of suicide threats and must therefore entail a genuine risk of serious injury or death. Failed attempts resulting in injury can still impose costs on group members and indicate the seriousness of future attempts. Completed suicides are the cost of maintaining a credible threat. A suicidal signaling/bargaining strategy could evolve if it involved warning others beforehand (allowing them to respond to the suicidal person's needs), if the rate of threats were much higher than the rate of attempts, and if the rates of attempts were much higher than the rate of completions. Under these circumstances, the average benefits received over many generations by genes coding for this strategy, when group members were successfully influenced, could exceed the average costs suffered by those genes when suicide attempts succeeded. ${ }^{8}$

In depression-related suicidality, individuals do commonly warn others of their intentions and frequently choose unreliable methods (Kreitman 1977; Stengel 1974). Major depression has been found to be by far the greatest risk factor for suicidal ideation, and the lifetime prevalence of suicidal ideation and attempts is several hundred times greater than the annual suicide rate (Table 6.3).

Across numerous studies, five psychological constructs have consistently been associated with suicide: impulsivity/aggression, depression, anxiety, hopelessness, and self-consciousness/social disengagement (Conner et al. 2001). Most of these are consistent with the bargaining model in obvious ways.

Previous research suggests that both clinicians (Bancroft et al. 1979; Hawton et al. 1982) and families (James and Hawton 1985) tend to attribute

Table 6.3 Rates of suicidal ideation and attempts are high compared to suicide rates.

\begin{tabular}{|c|c|c|}
\hline Annual suicide rate (age standardized) ${ }^{1}$ & $0.015 \%$ & WHO (2001) \\
\hline $\begin{array}{l}\text { Two-week prevalence of suicidal } \\
\text { ideation }\end{array}$ & $2.6 \%$ & Goldney et al. (2003) \\
\hline Lifetime prevalence of suicidal ideation $^{2}$ & $10-18 \%$ & Weissmann et al. (1999) \\
\hline Lifetime prevalence of suicide attempts ${ }^{2}$ & $3.5 \%$ & Weissmann et al. (1999) \\
\hline Suicide attempts per completion ${ }^{3}$ & $8-25$ & NIMH (2000); Platt et al. (1992) \\
\hline
\end{tabular}

${ }^{1}$ Worldwide rate for 1996; approximately four times as many men $(0.024 \%)$ as women $(0.0068 \%)$ commit suicide, a bias that is probably due to men choosing more lethal methods.

${ }^{2}$ Cross-cultural study based on self-report.

${ }^{3}$ Based on conservative criteria such as suicide attempt-related hospitalizations.

8 It may have been adaptive for very elderly or infirm individuals who were burdening their close kin to kill themselves reliably and without warning (deCatanzaro 1981). This does not account, however, for the large number of healthy, productive people who attempt suicide. (Suicide is among the three leading causes of death among young people 15-34 years of age [WHO 2001].) Healthy individuals who are suffering negative fitness due to costs imposed on their kin should simply leave the group. 
manipulative motives to suicide attempters, consistent with the bargaining model. Although studies of adolescents' stated reasons for suicide indicate that few mention a manipulative motive (e.g., in a study by Boergers et al. [1998], only $18 \%$ did so), numerous data from small, kin-based societies confirm that suicide threats are used by individuals for exactly the political purposes proposed here. Giddens's 1964 article on the cross-cultural sociology of suicide is worth quoting at length (citations in text omitted):

An example [of suicide as part of a wider social system of punishment and sanction in some societies] was given by Malinowski, in what has been recently described as "the best-known suicide in the ethnographic literature"... This was the case of a youth who committed suicide after he had been publicly accused of incest. This action, says Malinowski, served to expiate his crime. The suicide, by means of his act, "declares that he has been badly treated"...; the probability that a wronged or humiliated individual would kill himself serves as "a permanent damper on any violence of language or behavior, or any deviation from custom or tradition, which might hurt or offend another".... Suicide thus functions to facilitate social order; suicide, or the possibility of suicide, serves as a sanction in situations of controversy or dispute. A similar conclusion is reached by Berndt in a recent discussion of suicide.... Jefferys has collected together a number of examples of what he calls "revenge" suicide: in these examples, again, suicide functions as a form of social sanction against those towards whom the individual has a grievance.... Such suicide usually has ritualized elements in it - the suicide method, for example, is often standardized.

Attempted suicide and verbal threats of suicide, can also be seen in some societies to be part of a recognized social pattern. In Tikopia, for example, according to Firth, the suicidal threat is recognized as an appropriate response in certain types of situations. Verbal suicide threats are used as a form of social pressure in the judicial process. The announcement of intention to commit suicide draws public attention to the individual who believes himself wronged, and provides an indictment of the wrongdoer... A similar mechanism involving "a threat of suicide dramatically announced" operates, according to Honigman, among the Kashka Indians.... In Ovimbuandu, in central Angola, suicide threats are similarly used to put pressure on others in disputes; the suicidal threat is also recognized as an important form of social sanction among the Fulani.... Other examples are not hard to find. In all of these cases, suicide threats are part of a defined social pattern relating to the settlement of disputes.

Attempted suicide, of course, often simply represents a suicide which fails through technical reasons. But this is by no means always the case. Malinowski, for example, notes that, in the Trobriands, there are two "serious" methods used in suicide - these virtually always produce death; there is also a "milder" method, from which the individual usually recovers. The "milder" method is usually the one used in matrimonial quarrels and other relatively minor disputes.... Among the Kuma of New Guinea, suicide attempts are "expected" of women when they are contractually married. The suicide attempt is always by drowning. The attempt only occasionally results in the death of the individual. The suicide attempt is an accepted method of protest against the relatives who have brought about the undesired match.... Fortune describes various cases of attempted suicide in Dobu. Here 
attempted suicide is mainly associated with matrimonial disputes. The suicide attempt is typically made in the spouse's village, and serves as a means of registering protest, in front of relatives, against the conduct of the spouse.... Gorer remarks upon similar instances among the Lepchas of the Southern Himalaya. An individual who believes himself wronged may attempt to commit suicide; this serves both to affirm his own innocence in the matter in question, and as a public indictment of the transgressor. The individual attempts suicide, but the attempt is made "in such situations that he is bound to be saved"....

In all of these examples, the suicidal act is a recognized type of social mechanism, an accepted method of bringing pressure to bear upon others. (Giddens 1964, pp. 115-116)

Brown's (1986) detailed analysis of suicide among the Jivaroan Aguaruna, a group of hunter-horticulturalists who live in the rugged uplands of the Amazon in northern Peru, similarly reveals that the social etiology of suicides among this group is precisely that predicted by the bargaining model — suicide is used by individuals to impose costs on group members with whom they have a conflict:

Some segments of Aguaruna society — specifically, women and young men who are unable to organise collective responses to conflict — use solitary acts of violence directed against the self to express anger and grief, as well as to punish social antagonists. (Brown [1986], p. 311; emphasis added)

\section{Sex Bias}

Women are about twice as likely to suffer from a major depressive episode as men, a finding that, cross-culturally, is quite robust (e.g., Ustun and Sartorius 1995). Matching men and women by social role variables (e.g., employment, marriage status, and number of children) within cultures appears to reduce the female bias by about 50\% (Maier et al. 1999); the remaining bias has yet to be explained.

Under the bargaining model, women are expected to have higher rates of depression because (a) it was more often a better strategy for them, and (b) they had more conflicts with powerful others (cf. Wenegret 1995; Watson and Andrews 2002; MacKey and Immerman 2000). Women should have a lower threshold for, and higher rates of, depression than men because, in the EEA:

1. Physical aggression was a less-effective strategy for females in intersexual conflict.

2. Patrilocality ${ }^{9}$ meant that females, more often than males, were living with nonkin and were thus more likely to have conflicts with the group (e.g., Rodseth et al. 1991; see also Hess and Hagen, unpublished).

3. Female reproductive capacity was a scarce resource, so females were, more than males, victims of social manipulation by powerful others.

9 Males live with kin, females transfer - the modal pattern for humans. 
4. Most females could put scarce reproductive and childcare investment capacities at risk, whereas only some males had, for example, valuable hunting or military benefits to put at risk (i.e., there was less variability in female reproductive value relative to male reproductive value).

\section{Biochemistry}

The monoamine hypothesis of depression proposes that the physiological basis for depression is a deficiency of central noradrenergic and/or serotonergic systems, and that rectifying such deficiencies with an antidepressant would reduce or eliminate depression. Consistent with this hypothesis, the symptoms of depression can be alleviated by agents that, via several mechanisms, increase synaptic concentrations of monoamines, like serotonin and norepinephrine. This hypothesis has a number of problems, however, including the fact that it usually takes weeks or months of antidepressant treatment before depressive symptoms lift, even though antidepressants increase availability of the target neurotransmitters immediately. The hypothesis also fails to explain why depletion of serotonin does not cause depression in nondepressed subjects, nor does it exacerbate symptoms in depressed subjects (for review, see Bell et al. 2001). In addition, not all drugs which enhance serotonergic or noradrenergic transmission effectively treat depression. These and other deficiencies of the monoamine hypothesis are widely recognized, although it has by no means been abandoned (for a review, see Hirschfeld 2000).

According to the bargaining model, individuals should experience depression when they have potential conflicts with powerful others and cannot act unilaterally. Such circumstances would obviously induce long-term stress. Hundreds of studies have demonstrated increased levels of the stress hormone cortisol in depressed patients, and there is rapidly accumulating evidence that chronic activation of the HPA axis, the hormonal system that regulates the "fight-or-flight" (i.e., stress) response, is a proximate cause of depression. Pariante and Miller (2001, p. 391) summarize these findings in their review of the role of glucocorticoid receptors and stress hormones in major depression:

Hyperactivity of the HPA axis in patients with major depression is one of the most consistent findings in biological psychiatry. Specifically, patients with major depression have been shown to exhibit increased concentrations of [the stress hormone] cortisol in plasma, urine, and cerebrospinal fluid (CSF); an exaggerated cortisol response to adrenocorticotropic hormone (ACTH); and an enlargement of both the pituitary and the adrenal glands.... These HPA axis alterations are believed to be secondary to hypersecretion of corticotropin-releasing hormone $(\mathrm{CRH})$, which has behavioral effects in animals that are similar to those seen in depressed patients, including alterations in activity, appetite, and sleep....

Elevated levels of stress hormones among depressives were recognized even before antidepressants were discovered, but these changes were seen as 
epiphenomena of the stressful experience of depression. A vast amount of evidence has since accumulated that altered stress hormone secretions in depression are not epiphenomenal but are causally involved in its development and course. Further, there is evidence that traditional antidepressants may function by effecting changes in corticosteroid receptors; thus in the HPA axis, changes which then lead to clinical recovery (Holsboer 2000; Pariante and Miller 2001). In sum, considerable biochemical evidence is consistent with the bargaining model's prediction that certain kinds of social stress cause depression. ${ }^{10}$

\section{Other Etiological Factors and Findings}

Three factors that are important in the etiology of depression - genetic background, prior episodes of depression, and personality — do not clearly support the bargaining model, yet they are not inconsistent with it either. That there is a significant heritable component to unipolar depression is perhaps the strongest evidence against it being viewed as an adaptation. ${ }^{11}$ However, just as there could be heritable differences in thresholds for physical pain (which clearly is an adaptation), there could be heritable differences in depression thresholds or heritable differences in the likelihood of experiencing depressogenic events. Kendler and colleagues have found just this: A significant fraction of the heritable component of depression consists of heritable differences in the sensitivity to the environmental stimuli that trigger depression, and heritable differences in the likelihood of selecting oneself into environments that cause depression. That is, the genetic effects, at least in part, act on the environmental pathways to depression (e.g., Kendler et al. 2002).

Prior episodes of depression appear to be, in and of themselves, a cause of current episodes. Evidence is also accumulating that with each depressive episode, the association between stressful life events and a depressive episode decreases. Although early episodes are strongly correlated with stressful life events, later episodes onset with little apparent provocation (Kendler et al. 2000, 2001). This effect was strongest for those at low genetic risk. This "kindling" effect is probably responsible for the clinical observation that some cases of depression are not clearly related to life stressors. One functional interpretation of this effect is that defensive strategies become increasingly "hair-triggered." Much as the immune system becomes sensitized to specific antigens in order to

10 Of course, all biomedical researchers investigating depression assume that differences in biochemistry between depressed and nondepressed individuals reflect pathology. This appears, however, to be little more than an assumption.

11 Although studies consistently find that individual environmental factors play the largest role in the development of unipolar depression, various twin studies have found modest degrees of heritability, ranging from approximately $0.30-0.50$. There is also some evidence that depression might be more heritable in women than men (see, e.g., Bierut et al. 1999). 
respond with maximum speed and efficiency when it encounters them again, so, too, may social defense strategies become sensitized to social circumstances that are likely to reoccur and require a rapid and perhaps even preemptive response. It is also possible, of course, that the kindling effect is simply a by-product of the neurological changes that are associated with chronic stress.

Vulnerability factors, such as having a "neurotic" personality, also account for some of the variability in depression and are good predictors of future episodes. Although the origins of such personality factors are still obscure, they may be based on genetic background, experiences during childhood, and long-term exposure to particular social circumstances (e.g., Goldberg 2001). Given that an anxious disposition is a central feature of neuroticism, the vulnerability factor most reliably associated with depression, it is reasonable that "high-n" individuals believe themselves to be facing, or vulnerable to, social threats. If so, then neuroticism, whatever its origins, is understandably a "risk factor" for depression under the bargaining model.

A number of differences in cognitive performance between depressed and nondepressed individuals, typically involving memory, attention, and executive functions, have been well established (for a brief review, see Austin et al. 2001). These differences are widely interpreted as "deficits" indicative of an underlying neurological pathology. If depression is an adaptation, a number of cognitive differences along with their associated neuronal differences would also be expected between depressed and nondepressed individuals. The mere fact of differences is not, in and of itself, evidence that depression is a pathology, and it is possible that the documented differences are in fact related to adaptive functions of depression. Specific pathological models will have to be tested, both against functional models and against each other, to determine the best interpretation of these and the other data on depression.

\section{CONCLUSION}

Although effective in many circumstances, aggression and persuasion are poorly suited to resolve genuine conflicts between an individual and powerful others. Given the limited ability of ancestral groups to meet all the needs of all members, such conflicts would have been common, especially when most group members' social strategies were yielding benefits, but one individual's were not. If the individual had a monopoly, or near monopoly, on the benefits she was providing to the group, she could put these benefits at risk, forcing group members to provide assistance or bargain over the terms of the social contract. This strategy might have been particularly effective for women.

In the context of social conflict and feelings of entrapment/lack-of-control/helplessness, a severe negative life event frequently causes depression, especially among women. Depressive symptoms, such as sad or depressed mood, a loss of interest in virtually all activities, and suicidality, cause productivity to 
plummet. Despite negative feelings about the depressed, family members and other social partners consequently provide a surprising number of benefits, including increased concern, offers of advice, childcare and other forms of support, and decreased aggression.

Depression and suicidality in at least some of the small-scale, kin-based societies, which most closely resemble ancestral communities, are seen to be caused by loss, socially unacceptable anger, or "frustrated desires." Further, they are understood to redress losses and elicit help and concern from community members. Given the high degree of interdependence and reliance on reciprocity in these societies, it is difficult to imagine that depressive symptoms would not have such effects. Depression remits in association with fresh-start experiences and increased social support. Numerous biochemical investigations indicate that depression may be caused, not by neurotransmitter deficits per se, but by chronic stress.

The hypothesis that depression is an adaptation triggered by social costs that functions to compel social investment and change is supported by much of what is known about depression; however, finer-grained longitudinal studies will be required to determine adequately if depression can, in fact, cause meaningful and ultimately beneficial changes in social circumstances, or could have in the EEA. If so, then non-Western conceptualizations of depression, such as the Quechuan view of depression as an emotional strategy to restore the balance of reciprocity upset by loss, are largely correct, whereas the Western conceptualization of depression as a mental illness is largely incorrect.

\section{ACKNOWLEDGMENTS}

Many thanks to Leda Cosmides, Peter Hammerstein, Nicole Hess, Andy Thomson, John Tooby, Paul Watson, Aaron Sell, and members of the Center for Evolutionary Psychology lab group and Institute for Theoretical Biology for numerous comments and suggestions.

\section{REFERENCES}

Abramson, L.Y., G.I. Metalsky, and L.B. Alloy. 1989. Hopelessness depression: A theory-based subtype of depression. Psychol. Rev. 96:358-372.

Alexander, R.D. 1986.Ostracism and indirect reciprocity: The reproductive significance of humor. Ethol. Sociobiol. 7:253-270.

APA (American Psychiatric Association). 1994. Diagnostic and Statistical Manual of Mental Disorders. Washington, D.C.: American Psychiatric Assn.

Austin, M., P. Mitchell, and G.M. Goodwin. 2001. Cognitive deficits in depression. Brit. J. Psychiatry 178:200-206.

Axelrod, R., and D. Dion. 1988. The further evolution of cooperation. Science 242: $1385-1390$.

Bancroft, J., K. Hawton, S. Simkin et al. 1979. The reasons people give for taking overdoses: A further inquiry. Brit. J. Med. Psychol. 52:353-365. 
Beck, A.T. 1996. Depression as an evolutionary strategy. Presented at Annual Meeting of the Human Behavior and Evolution Society, June 27, Evanston, IL. Abstract. http://www.hbes.com/HBES/abst96.htm.

Beck, C.T. 1996. A meta-analysis of the relationship between postpartum depression and infant temperament. Nursing Res. 45:225-230.

Bell, C., J. Abrams, and D. Nutt. 2001. Tryptophan depletion and its implications for psychiatry. Brit. J. Psychiatry 178:399-405.

Benassi, V.A., P.D. Sweeney, and C.L. Dufour. 1988. Is there a relation between locus of control orientation and depression? J. Abnorm. Psychol. 97:357-367.

Bhattacharyya, D.P. 1981. Bengali Conceptions of Mental Illness. Ph.D. diss., Univ. of Michigan, Ann Arbor.

Bierut, L.J., A.C. Heath, K.K. Bucholz et al. 1999. Major depressive disorder in a community-based twin sample: Are there different genetic and environmental contributions for men and women? Arch. Gen. Psychiatry 56:557-563.

Boehm, C. 1996. Emergency decisions, cultural-selection mechanics, and group selection. Curr. Anthro. 37:763-793.

Boergers, J., A. Spirito, and D. Donaldson. 1998. Reasons for adolescent suicide attempts: Associations with psychological functioning. J. Am. Acad. Child Adoles. Psychiat. 37:1287-1293.

Bostwick, J.M., and V.S. Pankratz. 2000. Affective disorders and suicide risk: A reexamination. Am. J. Psychiatry 157:1925-1932.

Boyd, R., and P.J. Richerson. 1988. The evolution of reciprocity in sizable groups. $J$. Theor. Biol. 132:337-356.

Boyd, R., and P.J. Richerson. 1992. Punishment allows the evolution of cooperation (or anything else) in sizable groups. Ethol. Sociobiol. 13:171-195.

Brown, M.F. 1986. Power, gender, and the social meaning of Aguaruna suicide. Man New Series 21:311-328.

Brown, G.W. 1998. Genetic and population perspectives on life events and depression. Soc. Psychiat. Epidemiol. 33:363-372.

Campbell, S.B., J.F. Cohn, C. Flanagan et al. 1992. Course and correlates of postpartum depression during the transition to parenthood. Dev. Psychopathol. 4:29-47.

Clutton-Brock, T.H. 1991. The Evolution of Parental Care. Princeton, NJ: Princeton Univ. Press.

Clutton-Brock, T.H., and G.A. Parker. 1995. Punishment in animal societies. Nature 373:209-216.

Conner, K.R., P.R. Duberstein, Y. Conwell et al. 2001. Psychological vulnerability to completed suicide: A review of empirical studies. Suicide Life-threat. Behav. 31: 367-385.

Coyne, J.C. 1976. Depression and the response of others. J. Abnorm. Psychol. 85: $186-193$.

deCatanzaro, D. 1981. Suicide and Self-damaging Behavior: A Sociobiological Perspective. New York: Academic.

Fessler, D.M.T. 2003. The male flash of anger: Violent response to transgression as an example of the intersection of evolved psychology and culture. In: Missing the Revolution: Darwinism for Social Scientists, ed. J. Barkow. Oxford: Oxford Univ. Press, in press.

Figueredo, A.J., V. Corral-Verdugo, M. Frias-Armenta et al. 2001. Blood, solidarity, status, and honor: The sexual balance of power and spousal abuse in Sonora, Mexico. Evol. Hum. Behav. 22:295-328. 
Finch, J.F., M.A. Okun, G.J. Pool, and L.S. Ruehlman. 1999. A comparison of the influence of conflictual and supportive social interactions on psychological distress. J. Pers. 67:581-621.

Giddens, A. 1964. Suicide, attempted suicide, and the suicide threat. Man 64:115-116.

Goldberg, D. 2001. Vulnerability factors for common mental illnesses. Brit. J. Psychiatry 178 (40):s69-s71.

Goldney, R.D., E. Dal Grande, L.J. Fisher, and D. Wilson. 2003. Population attributable risk of major depression for suicidal ideation in a random and representative community sample. J. Affect. Disord., in press.

Hagen, E.H. 1996. Postpartum depression as an adaptation to paternal and kin exploitation. Human Behavior and Evolution Society 8th Ann. Conf., Northwestern Univ. Abstract. http://www.hbes.com/HBES/abst96.htm.

Hagen, E.H. 1999. The functions of postpartum depression. Evol. Hum. Behav. 20: $325-359$

Hagen, E.H. 2002. Depression as bargaining: The case postpartum. Evol. Hum. Behav. 23:323-336.

Harris, T. 2001. Recent developments in understanding the psychosocial aspects of depression. Brit. Med. Bull. 57:17-32.

Hawton, K., D. Cole, J. O'Grady, and M. Osborn. 1982. Motivational aspects of deliberate self-poisoning in adolescents. Brit. J. Psychiatry 141:286-291.

Henderson, S. 1974. Care-eliciting behavior in man. J. Nerv. Ment. Disord. 159: 172-181.

Hirschfeld, R.M. 2000. History and evolution of the monoamine hypothesis of depression. J. Clin. Psychiatry 61(6):4-6.

Holsboer, F. 2000. The corticosteroid receptor hypothesis of depression. Neuropsychopharmacology 23:477-501.

James, D., and K. Hawton. 1985. Overdoses: Explanations and attitudes in self-poisoners and significant others. Brit. J. Psychiatry 146:481-485.

Kendler, K.S., C.O. Gardner, and C.A. Prescott. 2002. Toward a comprehensive developmental model for major depression in women. Am. J. Psychiatry 159: $1133-1145$.

Kendler, K.S., R.C. Kessler, M.C. Neale et al. 1993. The prediction of major depression in women: Toward an integrated etiologic model. Am. J. Psychiatry 150:1139-1148.

Kendler, K.S., R.C. Kessler, E.E. Walters et al. 1995. Stressful life events, genetic liability, and onset of an episode of major depression in women. Am. J. Psychiatry 152:833-842.

Kendler, K.S., L.M. Thornton, and C.O. Gardner. 2000. Stressful life events and previous episodes in the etiology of major depression in women: An evaluation of the "kindling" hypothesis. Am. J. Psychiatry 157:1243-1251.

Kendler, K.S., L.M. Thornton, and C.O. Gardner. 2001. Genetic risk, number of previous depressive episodes, and stressful life events in predicting onset of major depression. Am. J. Psychiatry 158:582-586.

Kennan, J., and R. Wilson. 1993. Bargaining with private information. J. Econ. Lit. 31: 45-104.

Kreitman, N. 1977. Parasuicide. London: Wiley.

Lewis, A.J. 1934. Melancholia: A clinical survey of depressive states. J. Mental Sci. 80:1-43.

MacKey, W.C., and R.S. Immerman. 2000. Depression as a counter for women against men who renege on the sex contract. Psychol. Evol. Gender 2:47-71. 
Maier, W., M. Gansicke, R. Gater et al. 1999. Gender differences in the prevalence of depression: A survey in primary care. J. Affect. Disord. 53:241-252.

Mazure, C.M., M.L. Bruce, P.K. Maciejewski, and S.C. Jacobs. 2000. Adverse life events and cognitive-personality characteristics in the prediction of major depression and antidepressant response. Am. J. Psychiatry 157:896-903.

McElreath, R. 2003. Reputation and the evolution of conflict. J. Theor. Biol. 220: 345-357.

Nemeroff, C.B. 1996. The corticotropin-releasing factor (CRF) hypothesis of depression: New findings and new directions. Molec. Psychiatry 1:336-342.

Nesse, R. 1991. What good is feeling bad? The evolutionary benefits of psychic pain. Sciences 31:30-37.

Nesse, R. 1999. What Darwinian medicine offers psychiatry. In: Evolutionary Medicine, ed. W.R. Trevathan, E.O. Smith, and J.J. McKenna, pp. 351-373. Oxford: Oxford Univ. Press.

Nesse, R. 2000. Is depression an adaptation? Arch. Gen. Psychiatry 57:14-20.

NIMH (National Institute of Mental Health). 2000. Frequently Asked Questions about Suicide. http://www.nimh.nih.gov/research/suicidefaq.cfm.

Pariante, C.M., and A.H. Miller. 2001. Glucocorticoid receptors in major depression: Relevance to pathophysiology and treatment. Biol. Psychiatry 49:391-404.

Patel, V. 2001. Cultural factors and international epidemiology. Brit. Med. Bull. 57: 33-45.

Platt, S., U. Bille-Brahe, A. Kerkhof et al. 1992. Parasuicide in Europe: The WHO/EURO multicentre study on parasuicide. I. Introduction and preliminary analysis for 1989. Acta Psychiat. Scand. 85:97-104.

Presson, P.K., and V.A. Benassi. 1996. Locus of control orientation and depressive symptomatology: A meta-analysis. J. Soc. Behav. Pers. 11:201-212.

Price, J., L. Sloman, R. Gardner et al. 1994. The social competition hypothesis of depression. Brit. J. Psychiatry 164:309-315.

Rodseth, L., R.W. Wrangham, A.M. Harrigan, and B.B. Smuts. 1991. The human community as a primate society. Curr. Anthro. 32:221-254.

Rotter, J.B. 1966. Generalized expectancies for internal versus external control of reinforcement. Psychol. Mono.: Gen. Applied 80:1-28.

Rubinstein, A. 1982. Perfect equilibrium in a bargaining model. Econometrica 50: 97-109.

Schieffelin, E.L. 1985. The cultural analysis of depressive affect: An example from New Guinea. In: Culture and Depression, ed. A.M. Kleinman and B. Good, pp. 101-133. Berkeley: Univ. of California Press.

Segrin, C., and J.P. Dillard. 1992. The interactional theory of depression: A meta-analysis of the research literature. J. Soc. Clin. Psychol. 11:43-70.

Sheeber, L., H. Hops, and B. Davis. 2001. Family processes in adolescent depression. Clin. Child Fam. Psych. Rev. 4:19-35.

Shimbo, D., J. Child, K. Davidson et al. 2002. Exaggerated serotonin-mediated platelet reactivity as a possible link in depression and acute coronary syndromes. Am. J. Cardiol. 89:331-333.

Shostak, M. 1981. Nisa: The Life and Words of a !Kung Woman. New York: Vintage. Smith, J. 1999. Where the Roots Reach for Water: A Personal and Natural History of Melancholia. New York: North Point.

Spence, M. 1974. Market Signaling. Cambridge, MA: Harvard Univ. Press.

Stengel, E. 1974. Suicide and Attempted Suicide. New York: Penguin. 
Suarez, S.D., and G.G. Gallup. 1985. Depression as a response to reproductive failure. J. Soc. Biol. Struct. 8:279-287.

Thornhill, R., and N.W. Thornhill. 1989. The evolution of psychological pain. In: Sociobiology and the Social Sciences, ed. R.W. Bell and N.J. Bell, pp. 73-103. Lubbock: Texas Tech Univ. Press.

Tooby, J., and L. Cosmides. 1990. The past explains the present: Emotional adaptations and the structure of ancestral environments. Ethol. Sociobiol. 11:375-424.

Tooby, J., and L. Cosmides. 2000. Evolutionary psychology and the emotions. In: Handbook of Emotions, ed. M. Lewis and J.M. Haviland-Jones, 2d ed., pp. 91-115. New York: Guilford.

Tousignant, M., and M. Moldonado. 1989. Sadness, depression and social reciprocity in highland Ecuador. Soc. Sci. Med. 28:899-904.

Trivers, R.L. 1972. Parental investment and sexual selection. In: Sexual Selection and the Descent of Man, 1871-1971, ed. B. Campbell, pp. 136-179. Chicago: Aldine.

U.S. Dept. of Health and Human Services. 1993. Depression in Primary Care, vol. 2. Treatment of Major Depression. AHCPR Publication No 93-0551. Rockville, MD: U.S. Dept. of Health and Human Services.

Ustun,T.B., and N. Sartorius. 1995. Mental Illness in General Health Care: An International Study. Chichester: Wiley and Geneva: World Health Organization.

Vinokur, A.D., and M. van Ryn. 1993. Social support and undermining in close relationships: Their independent effects on the mental health of unemployed persons. J. Pers. Soc. Psych. 65:350-359.

Watson, P.J., and P.W. Andrews. 2002. Toward a revised evolutionary adaptationist analysis of depression: The social navigation hypothesis. J. Affect. Disord. 72:1-14.

Weissman, M.M., R.C. Bland, G.J. Canino et al. 1999. Prevalence of suicide ideation and suicide attempts in nine countries. Psychol. Med. 29:9-17.

Wells, K.B., A. Stewart, R.D Hays et al. 1989. The functioning and well-being of depressed patients: Results from the Medical Outcomes Study. J. Am. Med. Assn. 262:914-919.

Wenegrat, B. 1995. Illness and Power: Women's Mental Disorders and the Battle between the Sexes. New York: New York Univ. Press.

Whiffen, V.E., and I.H. Gotlib. 1993. Comparison of postpartum and nonpostpartum depression: Clinical presentation, psychiatric history, and psychosocial functioning. J. Consult. Clin. Psychol. 61:485-494.

WHO (World Health Organization). 2001. The World Health Report 2001. Health Systems: Improving Performance. Geneva: WHO.

Wolman, B.B. 1990. Preface. In: Depressive Disorders: Facts, Theories, and Treatment Methods, ed. B.B. Wolman and G. Stricker. New York: Wiley.

Wulsin, L.R., G.E. Vaillant, and V.E. Wells. 1999. A systematic review of the mortality of depression. Psychosom. Med. 61:6-17.

Zahavi, A. 1975. Mate selection: A selection for a handicap.J. Theor. Biol. 53:205-214. 